\title{
Programa de Qualificação de profissionais da informação em instituiçóes da saúde: parceria entre a Universidade Federal da Bahia e a Universidade do Porto
}

\author{
Zeny Duarte \\ Universidade Federal da Bahia (Brasil) \\ Armando Malheiro da Silva \\ Universidade do Porto (Portugal)
}

\section{Resumo}

Trata-se de proposta de mestrado profissional em ciência da informação (C.I.) com ênfase em informação e saúde em plataformas digitais, projecto a ser realizado conjuntamente pela Universidade Federal da Bahia (Ufba), Brasil e Universidade do Porto (UP), Portugal. Estudos interdisciplinares para a formação de pessoal capaz de interpretar o contexto produtor e utilizador da informaçáo visam aprofundar conhecimentos nas competências propostas pelo currículo do curso. A grade curricular possibilita actualizaçáo teórica e metodológica a diplomados que possuam experiência profissional em actividades relacionadas à C.I. e à saúde. O curso propóe desenvolver potencialidades na organização da informação em instituiçôes da área médica e em ambientes telemáticos. Como dispositivo metodológico para abordagem qualitativa do fenómeno informacional e quantitativa aplicável na C.I., as componentes curriculares direccionam-se às diversas operações de gestão da informação, da análise de itens documentais, de contextos produtores de fluxos informacionais, do uso, dos meios de acesso e dos instrumentos de controle da informação. A incidência da informação digital questiona condiçôes de integridade, de confiabilidade, inteligibilidade, de acesso múltiplo e em rede de documentos produzidos a partir do atendimento médico, clínico e hospitalar. O destaque serão as instituições da área da saúde, uma vez que produzem e acumulam informação e as transmitem a utilizadores mais imediatos. A longo termo, pretende-se fomentar a manutenção e salvaguarda dos acervos da memória institucional.

\begin{abstract}
The matter is the proposal for a professional master degree in information science (I.Sc.) with special emphasis on information and health in digital platforms, a project to be conducted jointly by the Federal University of Bahia and the University of Oporto (UP), Portugal. Interdisciplinary studies for the training of personnel able to interpret the information producing and using context aim at deepening the knowledge of the skills proposed by the course curriculum. The curricular program makes possible a theoretical and methodological updating to graduates with professional experience in activities related to the I.Sc. and health. The course proposes developing the students' potential in the information organization in medical institutions and in télématique environments. As a methodological device for a qualitative approach to the information phenomenon and for a quantitative one applicable in the I.Sc., the curriculum components lead to several operations of information management, of the documentary items analysis, of receiving data flows producing contexts, of use, of the access means and of the
\end{abstract}


information control tools. The incidence of digital information argues against the conditions of integrity, reliability, readability, multiple and virtual access to documents produced from medical, clinical and hospital care. The highlight of the course will be the institutions of the health care, for they produce and accumulate information and transmit it to more immediate users. A long-dated intent is the promotion of the maintenance and safeguard of the institutional memory holdings.

\section{Apresentação}

O Programa de Pós-Graduação em Ciência da Informação (PPGCI) da Ufba concentra-se na área da informação e conhecimento na sociedade contemporânea e nestas duas linhas de pesquisa: políticas, tecnologias e usos da informação; produção, circulação e mediação da informação. O objetivo principal é atender à demanda da sociedade local, regional e nacional, que requer a formaçáo de professores-pesquisadores na área, nos níveis de mestrado e doutorado. Desde a sua oficialização, em 1998, vem realizando acçôes proativas e inovadoras voltadas à educação continuada em C.I.. A partir de entáo, o PPGCI seleciona anualmente dezesseis alunos regulares para o mestrado académico (quatorze brasileiros e dois estrangeiros) e forma uma média de treze mestres. Em 2008, o programa apresentou à Coordenaçáo de Aperfeiçoamento de Pessoal de Nível Superior (Capes) o projecto do doutorado em C.I., que se encontra em fase de reescrita e complemento de informaçóes.

A proposta pedagógica desse programa alia a necessidade de formação de pesquisadores de alto nível à compreensão da contemporaneidade, marcada por intensas transformaçóes de variada natureza, activadas por um avanço científico e tecnológico dinâmico e impositivo. Essa visão de mundo resulta em desafio que vem conduzindo o seu corpo docente e discente ao reconhecimento dos amplos limites do estudo da informaçáo e conhecimento na sociedade contemporânea e à busca de ferramentas empíricas e fundamentos teóricos necessários ao desenvolvimento da C.I., enquanto área científica.

O perfil académico da comunidade do PPGCI é multidisciplinar e as investigaçóes por ela compreendidas apresentam-se num amplo arco de temas vinculados à informação, à mediação do conhecimento, a processos, produtos, tecnologias, gestão, usos, condicionamentos, teorias, métodos, terminologia, resgate de memória e história. Integrado exclusivamente por docentes com doutorado e pós-doutorado realizados no Brasil e noutros países, contando com apoio de órgáos de fomento à investigação em ciência, tecnologia e inovação, a exemplo da FCT, CNPq, Capes e Fapesb.

Após nove anos da instalação do mestrado em C.I., do fortalecimento e sedimentação do PPGCI, surge agora a necessidade da criação do primeiro mestrado profissional nessa área, quiçá o primeiro no Brasil com o perfil proposto.

O Mestrado Profissional em Ciência da Informação com Ênfase em Informação e Saúde em Plataformas Digitais (Mepis) surge para atender, sobretudo, à demanda reprimida do mercado de trabalho, respeitante à profissionalização na área da informação e saúde. Especificamente, o curso destina-se à qualificação de pessoal para atuar em instituiçóes documentais e informacionais na área da saúde. 
O Mepis segue as mesmas directrizes do PPGCI, mantém a mesma área de concentração, as mesmas linhas de pesquisa e o regimento interno. No entanto, a estrutura de seu projecto pedagógico é direccionada aos conteúdos consubstanciados no ensino e na prática teórica e metodológica, conforme o seu macroobjetivo: capacitar profissionais para o desenvolvimento permanente de práticas inovadoras em espaços profissionais concretos, habilitando-os para actuação de forma crítica na gestão das inovaçôes tecnológicas e na busca de soluçôes relacionadas ao planejamento e gestão da informação e à comunicação nas instituiçóes de saúde, em ciência e tecnologia associada.

\section{Contextualização do mepis}

Esse mestrado segue directrizes e regulamento da Capes e das normas complementares para funcionamento dos cursos de pós-graduação stricto sensu da Ufba, e as recomendaçôes do Aplicativo para Proposta de Curso Novo (APCN) 2009, determinadas por essa coordenação.

Uma das metas é atender às demandas nacionais no cenário de instituiçôes da área da saúde relacionada ao tratamento da informação produzida e acumulada durante décadas sem profissionais preparados e disponíveis para decisóes definidas e acertadas no gerenciamento da massa documental, com o fito de evitar a babel informacional e o descompasso irreversível no atendimento ao público. Na grande maioria dos casos, as empresas médicas não possuem profissionais qualificados para tratar os seus acervos e tampouco têm oportunidades para a formaçáo profissional em cursos semelhantes ao que ora se apresenta.

A realidade conhecida coloca desafios de vária ordem às disciplinas profissionais e profissionalizantes que se espera deem resposta concreta, como é o caso da arquivologia, da biblioteconomia e da documentaçáo, peças centrais de uma multi e transdisciplinaridade que baseiam uma concepção de C.I. integradora dessas disciplinas práticas e contributos parcelares, unificando-os e dando-lhes uma consistência científica que faz, naturalmente, a diferença no resultado final das soluçôes a propor. A realização do Mepis visa, assim, propiciar, por um lado, aos profissionais da informação uma sólida capacidade técnica e prática para intervirem plenamente na área da saúde onde se torna urgente racionalizar e tirar o máximo de eficiência e eficácia do fluxo informacional desde a produção, passando pela organização, pelo armazenamento, pela recuperação, uso e transformação da informação tanto clínica, quanto científica e a de caráter jurídico, administrativo e permanente; e, por outro, uma exigência teórico-metodológica que os conscientizem como cientistas da informação e, em última instancia, como cientistas sociais, embebidos, consequentemente, nas potencialidades e limitaçôes epistemológicas inerentes às ciências sociais aplicadas.

Evidencia-se a raridade de estudos aprofundados sobre a informaçáo produzida e acumulada em instituiçóes médicas, sobretudo com os enfoques conceptuais e contextuais da C.I. e da arquivologia. Essa é uma realidade em nível nacional e internacional. Apesar de a literatura fornecer um leque de estudos relativos à produção e uso da informação em organizações, mormente no âmbito da administração pública ou em instituiçôes académicas, a maioria deles carece de enquadramento teórico-metodológico. 
O ponto fulcral do Mepis será a oportunidade de verificar como se apresentam as instituiçôes da área da saúde quanto ao processamento da informação por elas produzida e como ocorre a relaçáo entre os setores informacionais e os usuários mais imediatos.

Sendo a informação gerada e estructurada pela acção e usada no contexto da actividade de seus produtores, pretende-se compreender a forma como é produzida e comunicada e se possibilita a sua transferência. Do contrário, os dados contidos nos documentos emanados do atendimento ao paciente e sua história médica se escondem e se perdem no emaranhado de documentos guardados inadequadamente e sem condições de acesso. Importa também verificar se a prática da gestão da informação favorece ou náo o acesso eficaz à recuperaçáo eficiente de documentos correntes e dados para fins de investigação retrospectiva. É preciso avaliar também a política de preservação e salvaguarda da memória informacional dos acervos constituídos a partir das actividades-meio e fim das instituições de saúde.

Para responder a essas e outras questôes, o mestrado profissional propóe estudos disciplinares com vista à formação de profissionais capazes de interpretar o contexto produtor e utilizador da informação. Além disso, como dispositivo metodológico para abordagens qualitativas do fenómeno informacional e quantitativas aplicáveis no âmbito da C.I., os conteúdos programáticos voltar-se-âo à gestão e uso da informação, à análise de contextos produtores dos fluxos informacionais, aos meios de acesso e instrumentos de investigação e controle de documentos tradicionais, analógicos e digitais.

- A formação de mestre profissional em informação e saúde em plataformas digitais exigirá estudos sobre preservação da informação, tendo em vista o resgardo das condiçôes de integridade, confiabilidade, inteligibilidade e acesso múltiplo e em rede. Em particular, será dada ênfase à avaliaçáo tanto retrospectiva quanto prospectiva do fluxo informacional, com aplicaçáo de modelos desenvolvidos para o alcance da metainformação descritiva, hoje indispensável ao acesso aos recursos necessários ao desenvolvimento de estudos em C.I..

Com a instalação do Mepis, buscar-se-á o aprofundamento de conhecimentos de profissionais com perfil para assumir competências propostas em seu plano pedagógico a partir de iniciativas práticas apresentadas pelos mestrandos. Ademais, a grade curricular possibilitará qualificação e actualização teórica e metodológica a formados de outras áreas científicas que detenham experiência bipolar entre a C.I. e saúde.

\section{Histórico do curso}

A proposta de criaçáo do Mepis foi idealizada a partir do projecto de pósdoutoramento da Profa. Zeny Duarte, realizado na Faculdade de Letras da UP, sob a orientação do Prof. Armando Malheiro da Silva e com o imprescindível apoio da FCT. No percurso de seus estudos, precisamente em 19 de dezembro de 2007, foi firmado o aditivo (adenda) ao protocolo de colaboração académica e científica entre a Universidade Federal da Bahia e a Universidade do Porto, Portugal, com as assinaturas dos reitores de ambas as universidades e dos directores das instituiçóes de ensino envolvidas.

Esse documento de cooperaçáo bilateral foi acolhido pelos reitores das universidades mencionadas, Prof. Dr. Naomar Monteiro de Almeida Filho e Prof. Dr. José Carlos Diogo Marques do Santos, coordenado pela Profa. Dra. Zeny Duarte, docente do 
Instituto de Ciência da Informação - Ufba e pelo Prof. Dr. Armando Malheiro da Silva, da Secção Autónoma de Jornalismo e Ciências da Comunicação da Faculdade de Letras da UP. A partir de então, os esforços foram centrados na implementação do primeiro Colóquio Internacional "A Medicina na Era da Informaçâo" (Medinfor) e na criação do mestrado profissional em C.I..

O Medinfor foi realizado em outubro de 2008 pela Ufba em parceria com a UP, com apoio da Capes, Fundação de Amparo à Pesquisa do Estado da Bahia (Fapesb) e de instituiçóes ligadas as áreas da C.I. e da saúde. Essa foi uma feliz oportunidade para transmitir ao público interessado conferências e comunicaçóes de expoentes internacionais e nacionais com experiências reconhecidas nas áreas da informação, saúde e preservação da memória. Na altura, pôde-se verificar a necessidade de ampliação de meios que oportunizem a formação de recursos humanos para actuar na gestão da informação em sectores da saúde.

\section{Intercâmbio cientício e cultural - Portugal e Brasil}

A adequação do projecto Mepis está sendo analisada por professores doutores das universidades promotoras, UP e Ufba. A partir do convénio firmado, a UP tem estimulado a concretização de investigação, reunióes técnico-científicas, planos de cursos e publicaçóes, além do fortalecimento do intercâmbio entre professores e alunos. Durante o mestrado, e a depender do seu projecto de pesquisa, o aluno terá chance de realizar parte de seus estudos na UP, co-orientado por professores doutores da Faculdade de Letras e da Faculdade de Engenharia. Outra possibilidade de intercâmbio é a ida para a Ufba de professores dessa universidade portuguesa para ministrar disciplinas, a fim de ampliar as possibilidades de transmissáo de conhecimentos relacionados aos conteúdos programáticos obrigatórios, conforme dito no item anterior.

Como estratégia de implantação, serão estimuladas parcerias intrainstitucionais, com programas de pós-graduação da Ufba, de modo especial com aqueles das áreas da saúde, da ciência da computação, matemática e engenharia, pois é com base na capacidade científica e técnica dos que atuam nesses campos do conhecimento que o novo programa alcançará o sucesso almejado.

Instituiçôes científicas e culturais com credibilidade académica e científica no campo temático do mestrado poderão colaborar através de instrumentos já existentes, como, por exemplo, os dos mestrados profissionais em ciências sociais aplicadas. Avalia-se a proposta de organização de uma rede de informação de instituiçóes de saúde, coordenada pela Ufba e UP, como partida inicial à perspectiva de criaçáo de outras plataformas de informação compartilhada.

\section{Estrutura do mepis}

\subsection{Princípios gerais}

- A iniciativa objectiva apresentar impacto significativo na actuação dos gestores, com a criaçáo de um campo permanente de inovaçóes e debates da política de CT\&I 
em saúde e do papel das instituiçóes no desenvolvimento do sistema nacional de inovaçóes.

- Os alunos que cumprirem os requisitos de frequência, de aproveitamento e elaboraçáo do trabalho de conclusão devidamente aprovado por uma banca examinadora, receberão o diploma de mestre em C.I com ênfase em informação e saúde em plataformas digitais, nível profissionalizante.

- O corpo docente deste curso é formado por pesquisadores-doutores e mestres credenciados no programa de pós-graduação da Ufba e da UP, que desenvolvam seus projectos nas linhas de pesquisa do curso, voltados para as áreas de informação e saúde. Também por profissionais ligados a diferentes áreas de actuação, reconhecidos por sua experiência e por suas práticas inovadoras.

- O Mepis destina-se a profissionais graduados com experiência profissional na área da informação e deve atender à demanda de profissionais com graduação em diferentes áreas do conhecimento, que atuem em espaços múltiplos em que haja necessidade de gerir a informação e o conhecimento como actividade-meio e actividade-fim. O desempenho desses profissionais (quer sejam eles consultores na área da organização empresarial, quer responsáveis por centros de informática, administradores de bibliotecas, arquivos e centros de informação e documentação, ou profissionais da informaçáo) sinalizará a evidência de que a informação é recurso-chave para o sucesso das instituiçôes.

- O Mepis tem como meta primordial preparar profissional capaz de aplicar conhecimentos, de resolver problemas em ambientes novos ou desconhecidos e nos contextos genéricos da área correspondente à constituição dos conjuntos documentais, também capacitado para avaliar situaçôes, desenvolver estudos de análise e síntese, comunicar conclusôes a públicos de especialistas ou não. O dipliomado deve estar apto a conhecer a natureza da informaçáo acumulada e processada, o ciclo de vida dos documentos, os diversos modos de sua produção e os aspectos legais e éticos de acesso e uso, independentemente do suporte em que a informação esteja registada.

O curso apresenta-se na perspectiva da proposta do Programa de Apoio a Planos de Reestruturação e Expansão das Universidades Federais do Brasil (Reuni). Articular-se-âo actividades de ensino, extensão e pesquisa, enfatizando a produção do conhecimento e a inovação como pontos de chegada e oportunidades na formação técnico-científica aprofundada para a actuação profissional extrauniversidade.

\subsection{1 Área de concentração e linhas de pesquisa}

O programa disponibilizará investigações na área de concentração em informação e conhecimento na sociedade contemporánea. Centrar-se-á no domínio dos estudos sociais e humanos da informação e em estudos sociais aplicados do documento e das TIC. A área em que se concentram as atividades do PPGCI da Ufba expressa a opção dos docentes pela investigação de duas vertentes do fenómeno/processo informacional: por um lado, as necessidades informacionais e as políticas, infraestruturas e tecnologias, e, por outro lado, a mediação da informação e a mediação para o uso da informação, focalizadas no âmbito dos fenómenos/processos comunicacionais, cognitivos e sociais.

Tratar-se-á a gestão da informação em instituiçôes de saúde, voltada ao planeamento e estratégia no acesso, recuperação e compartilhamento de itens documentais. Realizar-se- 
ão estudos teóricos, práticos e metodológicos aplicados aos procedimentos de mediação da informação na área da saúde, com o aporte de tecnologia e inovação. Utilizar-se-ão as TIC e as possibilidades de experimentos de organização da informação em redes sociais a partir de documentos gerados em ambientes hospitalares, em clínicas médicas e noutras instituiçóes de saúde.

Quanto às linhas de pesquisa, o Mepis contemplará estudos voltados às políticas, tecnologias e usos da informação. Assim sendo, serão bem-vindos estudos teóricos e aplicados sobre as políticas e os usos da informação, do documento e de suas tecnologias e infraestrutura. Interessará ao Mepis a apresentação de modelos, produtos e instrumentos de organizaçáo, acesso e recuperação da informação. Os projectos devem prever monitoramento de necessidades, comportamentos e hábitos informacionais, assim como padróes de funcionamento e regulagem de redes e sistemas de informação. Partindo para o plano científico e histórico, serão consideradas relevantes investigaçóes em torno de tendências e indicadores de produção científica, de identidade e memória, por meios de mecanismos e metodologias de preservação e salvaguarda.

Por outro lado, o Mepis direccionará estudos teóricos e aplicados sobre o tratamento da informação visando a seu uso no âmbito dos fenómenos/processos comunicacionais, cognitivos e sociais. A abordagem teórica e metodológica passará pela transferência da informação por ciclos e fluxos em diferentes meios e contextos. O curso voltarse-á aos estudos sobre acesso, circulação, disseminação, uso da informação em vários contextos e adopção de redes sociais e humanas de intercâmbio. Considerando a especificidade da formação, os estudos contemplarão padróes de funcionamento de sistema de informação, plataformas digitais e a Internet.

\section{Conclusão}

Apresenta-se, em linhas gerais e mestras, um projecto a ser desenvolvido a partir de articulação estreita entre os investigadores nos campos da C.I e da saúde, procurandose criar um modelo destinado à salvaguarda e acesso da memória informacional, para pesquisas sobre informaçôes atuais e do passado aplicáveis em contextos congêneres. Propóe-se, também, complementar o estudo com a otimização da aplicação dos meios informáticos passíveis de suportar a metainformação descritiva, indispensável ao acesso e uso dos recursos necessários ao desenvolvimento da investigação médica e à extração de indicadores e relatórios acerca da produção, uso da informação e comunicação dos resultados da busca de dados informacionais. 